\title{
BMJ Open Evaluation of types of poisoning exposure calls managed by the Malaysia National Poison Centre (2006-2015): A retrospective review
}

\author{
Balamurugan Tangiisuran, ${ }^{1,2}$ Maryam Jiva, ${ }^{3}$ Adilah Mohamed Ariff, ${ }^{1}$ \\ Noor Afiza Abdul Rani, ${ }^{1}$ Asdariah Misnan, ${ }^{1}$ Sazaroni Md Rashid, ${ }^{1}$ \\ Mohamed Isa Abdul Majid, ${ }^{1}$ Andrew H Dawson ${ }^{4}$
}

To cite: Tangiisuran B, Jiva M, Ariff AM, et al. Evaluation of types of poisoning exposure calls managed by the Malaysia National Poison Centre (2006-2015): A retrospective review. BMJ Open 2018;8:e024162. doi:10.1136/ bmjopen-2018-024162

- Prepublication history for this paper is available online. To view these files, please visit the journal online (http://dx.doi. org/10.1136/bmjopen-2018024162).

Received 21 May 2018 Revised 27 July 2018 Accepted 11 October 2018

Check for updates

(c) Author(s) (or their employer(s)) 2018. Re-use permitted under CC BY-NC. No commercial re-use. See rights and permissions. Published by BMJ.

${ }^{1}$ National Poison Centre, Universiti Sains Malaysia, 11800 USM, Penang, Malaysia ${ }^{2}$ School of Pharmaceutical Sciences, Universiti Sains Malaysia, 11800 USM, Penang, Malaysia

${ }^{3}$ Institute of Pharmaceutical Sciences, Kings College London, London, UK

${ }^{4}$ Royal Prince Alfred Hospital and Sydney Medical School, University of Sydney, Sydney, New South Wales, Australia

Correspondence to

Dr Balamurugan Tangiisuran; bala@usm.my

\section{ABSTRACT}

Objective Accidental or intentional poisoning is a public health concern requiring intervention. The current study designs to evaluate the types of poisoning exposure calls received by the Malaysia National Poison Centre (NPC) over a 10-year period.

Settings and data sources The poisoning enquiries database (2006-2015) from the Malaysia NPC was used for the analysis

Participants The NPC records all telephone calls that it manages using a validated and standardised form. Demographics and types of the poisoning exposure calls were extracted and descriptive analysis was applied. Primary and secondary outcomes The primary outcome of this study is to evaluate NPC data for trends in the poisoning exposure calls based on the types and modes of poisoning over a 10-year period. The secondary outcome is to evaluate the characteristics of human exposure cases based on the calls received by the NPC.

Results There was a notable increase in the number of poisoning exposure calls noticed during the 10-year period but dropped significantly in 2012. The highest number of poisoning exposure calls came from Selangor $(21.0 \%)$, Perak (18.0\%) and Negeri Sembilan (9.8\%). More than half of the exposure was intentional (53.8\%) involving more women (50.3\%) as compared with men (41.9\%), and in the 20-29 years age group category (33.5\%). Exposure mostly occurred at home (96\%) through the ingestion route $(94.1 \%)$. Pharmaceutical products $(40.5 \%)$, pesticides $(31.7 \%)$ and household products $(20.1 \%)$ were the common agents implicated for intentional exposure. Conclusions There is an increasing trend in enquiries on poisoning exposure calls made to the NPC. Most of the intentional poisoning exposures occurred among younger women and involved pharmaceuticals, pesticides or household products. Poisoning safety education and other interventions are needed to curb poisoning incidents.

\section{INTRODUCTION}

WHO deems poisoning to be a globally significant threat to public health. The WHO Global Burden of Disease project revealed an estimated 345814 people of all ages died
Strengths and limitations of this study

- This study revealed a long-term trend on poisoning exposure calls received at a national poison centre in a South-East Asian country over a 10-year period.

- The data reported depend on the self-reported calls made by healthcare providers based on the calls received relating to exposure to a substance that required management in the healthcare facilities.

- The common types of poisoning, the causative agents and characteristics of patients were confirmed through telephone conversation.

- The data set lacks complete follow-up on the patient's management, outcomes and severity of poisoning.

- The causes of and reasons for the exposure are also not investigated in detail, indicating a general lack of complete poisoning surveillance in the country.

worldwide as a result of 'accidental' poisoning in 2004. ${ }^{1}$ Low-income and middle-income countries have higher poisoning death rates than high-income countries. ${ }^{1}$ The prevalence and types of poisoning vary considerably across the world and depend on socioeconomic status and cultural practices, as well as on local industrial and agricultural activities. ${ }^{2}$

Poison centres are established to provide assessment, triage, management and continued monitoring of poisoning cases in a country. ${ }^{3}$ Concurrently, the available data can be used for planning of suitable interventional strategies to reduce both intentional and unintentional poisoning in a population. However, of all 11 countries currently making up the South-East Asia region, only a mere 7 have an operational poison centre as of August 2016. Burma, Cambodia, Indonesia, Malaysia, Philippines, Thailand and Vietnam have functional poison centres, while Laos, Singapore, Brunei and East Timor lack such a 
facility. ${ }^{4}$ The Malaysia National Poison Centre (NPC) was first established in $1994 .{ }^{5}$ It is the main centre providing toxicological information to healthcare providers and the general public, serving a population of over 31 million people.

In relation to data collection and publication of findings by the aforementioned poison centres, the few reports that currently exist focus on specific poisoning agents, modes or demographic factors associated with poisoning within these countries. ${ }^{6}$ What is apparent following literature searches on this topic, however, is the absence of reporting of the wider profile of poisoning enquiries within countries and a lack of overviews detailing the national trends seen by South-East Asian poison centres in their respective countries. An overall depiction of the type of enquiries received by these poison centres would prove most valuable in highlighting national trends associated with poisoning cases in the respective countries. Hence, the primary aim of this study is to evaluate the types of poisoning exposure calls received by the Malaysia NPC for the period from 2006 to 2015.

\section{METHODS}

\section{Data source}

A retrospective review of the NPC database was conducted. The entire population of Malaysia is served by only one poison centre. The Drug and Poison Information Service of the NPC has attended to a wide continuum of poisoning-related enquiries since its inception in 1994, and has received over 42000 poisoning exposure calls to date. Since then, the centre has noted an annual increase in the number of calls received.

All telephone calls received by the centre are entered into a standardised Poison Case Report Form (PCRF), adapted from the WHO IPCS INTOX system. ${ }^{7}$ The PCRF has been modified and updated thrice since 1995. The face and content validity were previously established by several academicians and nine pharmacists. The PCRF consists of five domains: administrative records, patient's background, poisoning information, clinical features and patient management. Information on clinical features and patient management on admission before contact with the centre were obtained at the centre's initiative previously but this segment is now officially incorporated in the PCRF after 2011.

Call details obtained from the caller uses a systematic approach that includes the enquirer's contact details, patient's age, sex and weight ( $\mathrm{kg}$ ), type(s) of poisoning agent involved, quantity ingested (if applicable), location of the incident, circumstances of exposure, route of exposure and the time elapsed after the patient's initial exposure to the interlocutor agent.

Classification of poisoning agents are based on the WHO INTOX system classification. ${ }^{7}$ Each agent is classified as either agricultural/garden, environmental contaminant, food and beverages, household/leisure, industrial/commercial, natural toxins, pharmaceuticals, pesticides, or substances of abuse. Additionally, each poisoning enquiry is classified either as intentional, unintentional or adverse reactions based on the WHO INTOX classification. ${ }^{7}$ An intentional incidence is defined as 'an exposure by any route (or incident) where there was an intention to cause harm'. An unintentional incidence is defined as 'an exposure by any route (or incident) where there was no intention to cause harm'. An adverse reaction is defined as 'an unwanted effect of a drug, food or other agent occurring after the normal use of that agent'. In this study, exposures do not necessarily represent a poisoning or overdose. ${ }^{8}$

A team of nine specially trained inhouse pharmacists handles all poisoning exposure calls and the information on each call is documented. Information sought by the caller is conveyed based on reference from databases such as, Micromedex (Poisondex) and Toxinz or primary literature for unique cases. For enquiries that can be dealt with via general measures including certain snakebites, pharmaceutical overdoses (eg, acetaminophen/certain prescription medications) and pesticide ingestion for instance, the pharmacists provide immediate treatment advice and guidance to the caller. They assist in the triage of a patient, advise on first aid and signpost to nearby healthcare facilities equipped to deal with such cases.

\section{Inclusion and exclusion criteria}

Poisoning exposure calls made by the healthcare providers from healthcare institutions across Malaysia between January 2006 to December 2015, complete with information on the PCRF and database, were included in this study. General poisoning enquires both by the general public and healthcare providers were excluded in this study.

\section{Data analysis}

Data analyses were performed using the Statistical Package for Social Sciences (SPSS) V.24.0. Descriptive statistics was performed and results were presented in frequency and percentages.

\section{Ethical approval}

The patient case data collated between January 2006 and December 2015 were used as a component of this study. All personal details pertaining to the patients were removed prior to descriptive analysis, to ensure anonymity of individuals.

\section{Patient and public involvement}

Patients and public were not involved in the development of the research questions and also in the design of this study. All information was obtained through the poisoning exposure calls received by the NPC from the healthcare providers. The results will be disseminated via our local authorities, conference presentations and shared through patient and public involvement initiatives by the NPC. 


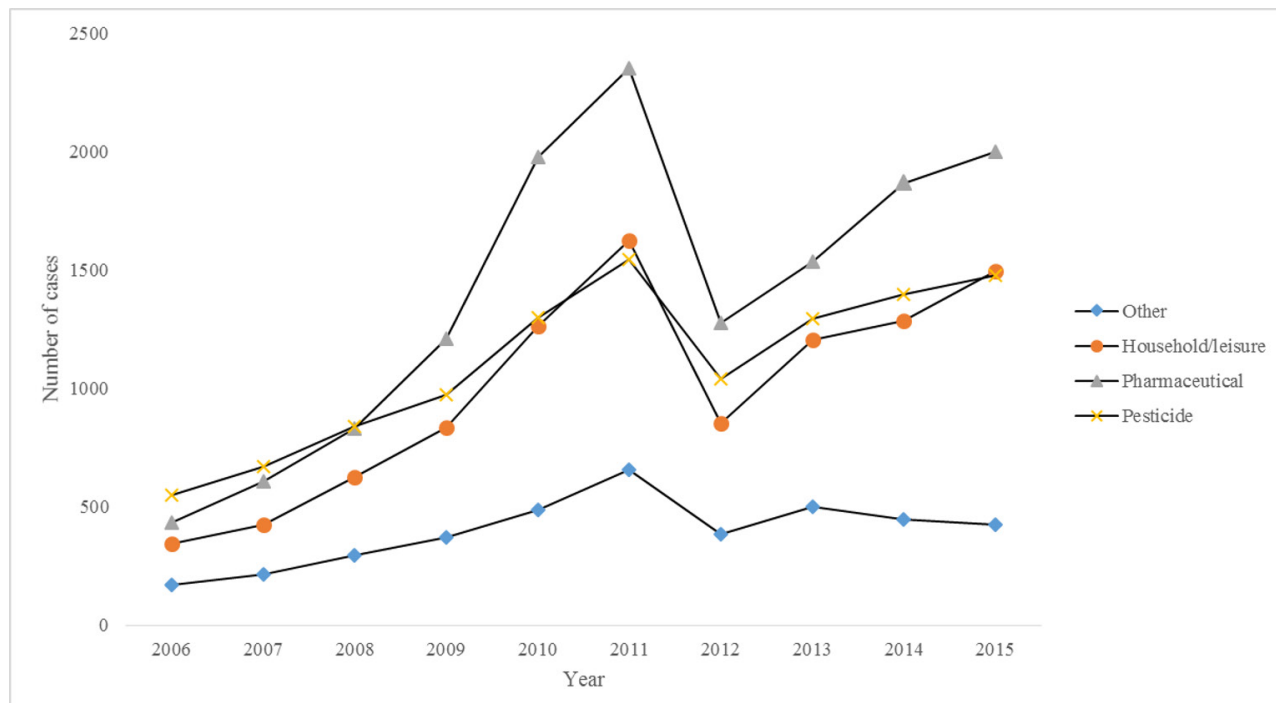

Figure 1 Trends of the three most common poisoning exposure agents based on the calls received by the Malaysia National Poison Centre between 2006 and 2015. The series titled; 'other' was inclusive of the remainder of poisoning agent categories. These were: agricultural/garden, environmental contaminant, food and beverages, industrial/commercial, natural toxins, substances of abuse, mixture of agents, other and unknown.

\section{RESULTS}

During the study period, the NPC had handled 39088 poisoning exposure calls for consultation. Figure 1 demonstrates an increasing trend of poisoning exposure calls made to the NPC from the years 2006 to 2011, followed by a sharp drop in the year 2012 and a steady increase 2013 onwards. The highest number of calls were received from Selangor $(21.0 \%)$, Perak $(18.0 \%)$, and Negeri Sembilan $(9.8 \%)$. The least calls were received from Terengganu (0.6\%); Labuan $(0.1 \%)$, followed by Perlis $(0.1 \%)$ (table 1$)$. Of the total poisoning exposure calls received, $63.1 \%$ were calls outside office hours and $72.5 \%$ of calls were made on weekdays.

In terms of demographic distribution, men and women constitute almost equal number of poisoning exposure calls $(47.0 \%$ vs $41.5 \%)$. There were more poisoning exposure calls related to Malay ethnicity $(28.4 \%)$, followed by Indian $(26.1 \%)$, Chinese (13.5\%) and others. In general,

Table 1 Total number of poisoning exposure calls received by the National Poison Centre from each state in Malaysia between 2006 and 2015

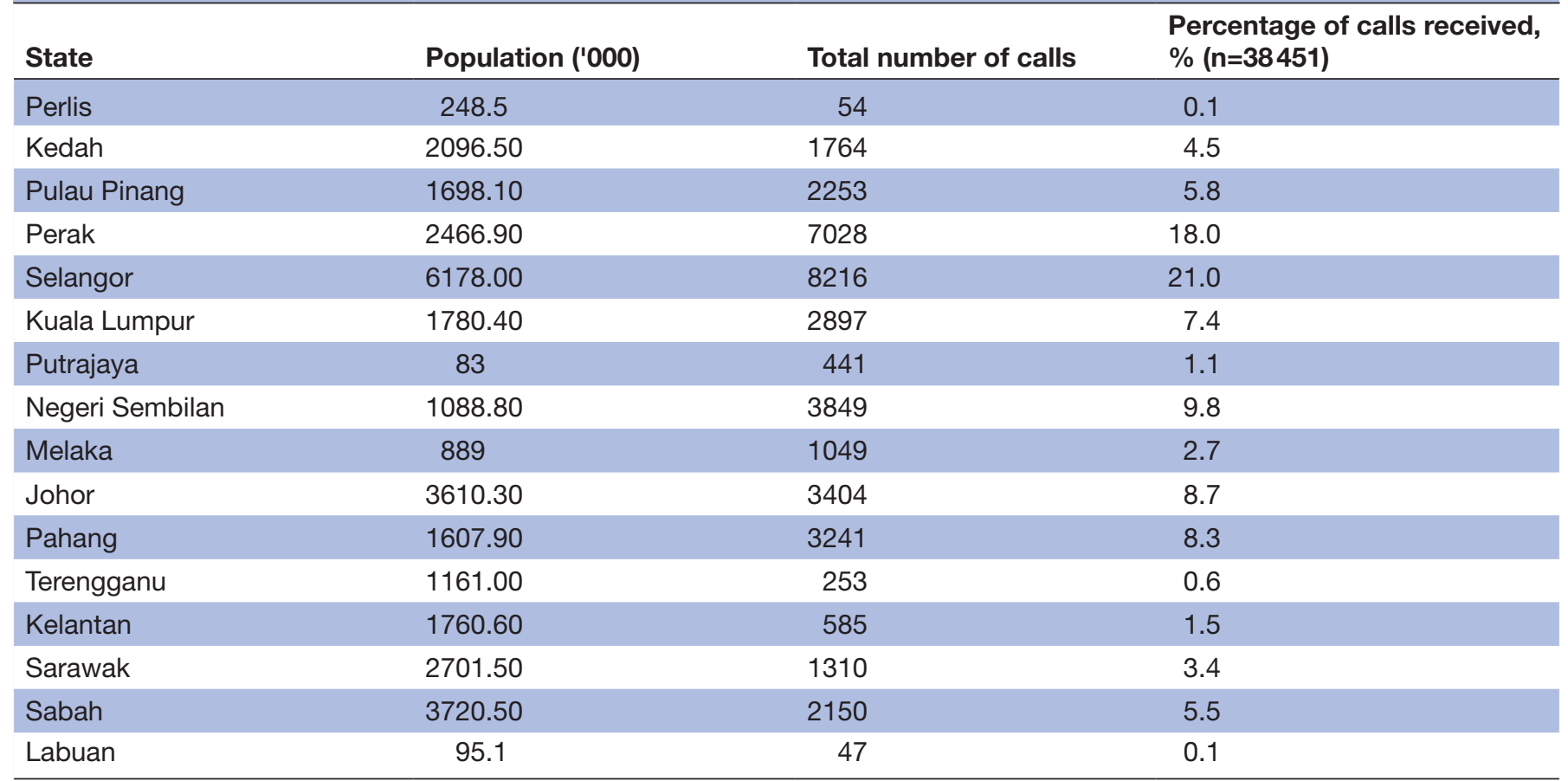

The total Malaysian population was 31186.10 million in 2015 (Department of Statistics, Malaysia). 
the majority of the poisoning exposure calls were related to exposure of pharmaceutical products $(36.0 \%)$, pesticides $(28.4 \%)$ and household products $(25.5 \%)$. Poisoning exposure occurring at home stood at $92.8 \%$. Poisoning exposure at the agriculture or horticulture site accounted for $48.5 \%$ and at factories $27.4 \%$. The number of intentional poisonings outweighed unintentional poisonings $(53.8 \%$ vs $44.0 \%$, respectively) with only $1.0 \%$ of cases due to adverse reactions. Most poisoning exposure calls were associated with acute exposure (95.3\%), primarily through oral ingestion (94.1\%) (table 2).

Under the intentional poisoning category, half of the poisoning exposure calls received involved women $(50.3 \%)$ as compared with men $(41.9 \%)$. The highest number of intentional poisonings occurred in the 20-29 years (33.5\%), 30-39 years $(19.7 \%)$ and $40-49$ years $(10.3 \%)$ age groups. On the other hand, unintentional poisoning involved more men $(53.3 \%)$ as opposed to women. Majority of the unintentional poisoning cases occurred in the 1-9 years age group $(46.7 \%)$, followed by 19-29 years $(13.4 \%)$ and $30-39$ years $(8.8 \%)$ (table 3 ).

Table 4 demonstrates that the pharmaceutical products $(40.5 \%)$ and pesticides $(31.7 \%)$ are common agents implicated in intentional poisoning. As for the unintentional poisoning category, household or leisure products $(32.7 \%)$ and pharmaceuticals $(30.0 \%)$ are the contributory factors. A high proportion of poisoning exposure calls were related to adverse reactions attributed to pharmaceuticals (64.4\%).

\section{DISCUSSION}

This study details poisoning trends identified over a 10-year period based on the poisoning exposure calls received at the Malaysia NPC. As observed, there is a sharp rise in the number of poisoning exposure calls received from 2006 to 2011, and a significant decline in the year 2012. The decline in the number of calls in the latter year was concurrent with a change of operating hours at the NPC during that time. Faced with budgetary constraints, the NPC Drug Poison Information Service was forced to temporarily withdraw its $24 / 7$ service, limiting it to regular office hours. The NPC reverted to its previous operational arrangement after a 6-month break.

Majority of the poisoning exposure calls serviced by the NPC over the 10-year period were from the state of Selangor. Selangor is Malaysia's most economically developed state and has the highest population density relative to the country's other states. Fewer calls were received from East Malaysia that has experienced urbanisation to a lesser degree. Previously published literature has investigated the relationship between the extent of urbanisation and poisoning exposure. A previous US study highlighted that urbanisation rate has an effect on deaths due to drug poisoning in particular. ${ }^{9} \mathrm{An}$ Irish study further confirmed a higher mortality rate due to poisoning in urban areas during 1980-2000. ${ }^{10}$

In this study, it is evident that a higher proportion of women was involved with intentional poisoning whereas
Table 2 Sociodemographic characteristics of the human exposure cases which led to the poisoning exposure calls received by the National Poison Centre (total $=39088$ )

\begin{tabular}{lr}
\hline Sociodemographic characteristics & Frequency (\%) \\
\hline Gender & \\
Male & $18374(47.0)$ \\
Female & $16208(41.5)$ \\
Unknown & $4506(11.5)$ \\
Race & \\
Malay & $11107(28.4)$ \\
Chinese & $5263(13.5)$ \\
Indian & $10190(26.1)$ \\
Other & $3135(8.0)$ \\
Non-Malaysian & $578(1.5)$ \\
Unrecorded/unknown & $8815(22.6)$
\end{tabular}

Type of poisoning

Pharmaceutical

$14081(36.0)$

Pesticide

11087 (28.4)

Household leisure $9957(25.5)$

Others

$3963(10.1)$

Location of incident

Home

36258 (92.8)

Workplace

1094 (2.8)

Open place

$267(0.7)$

Hospital/clinic

$245(0.6)$

Academic institution

$64(0.2)$

Other

1159 (2.9)

Incidence category

$\begin{array}{lr}\text { Intentional } & 21017(53.8) \\ \text { Unintentional } & 17195(44.0) \\ \text { Adverse reaction } & 374(1.0) \\ \text { Unrecorded } & 502(1.3) \\ \text { Exposure type } & \\ \text { Unknown } & 277(0.7) \\ \text { Acute } & 37260(95.3) \\ \text { Chronic } & 251(0.6) \\ \text { Acute on chronic } & 1295(3.3)\end{array}$

Exposure route

\begin{tabular}{lc} 
Ingestion & $36764(94.1)$ \\
Inhalation & $1000(2.6)$ \\
Cutaneous & $276(0.7)$ \\
Ocular & $137(0.4)$ \\
Bite/sting & $632(1.6)$ \\
Injection & $133(0.3)$ \\
Mucosal & $34(0.1)$ \\
Placental & $9(0)$ \\
Otic/aural & $2(0)$ \\
Others & $23(0.1)$ \\
Unrecorded & $78(0.2)$ \\
\hline
\end{tabular}

Tangiisuran B, et al. BMJ Open 2018;8:e024162. doi:10.1136/bmjopen-2018-024162 
Table 3 Frequency of poisoning modes (intentional poisonings, unintentional poisonings and adverse reactions) by different age categories based on poisoning exposure calls received at the Malaysia National Poison Centre, 2006-2015

\begin{tabular}{|c|c|c|c|}
\hline & Intentional poisonings & Unintentional poisonings & Adverse reactions \\
\hline Variable & $\mathrm{N}(\%)$ & $\mathbf{N}(\%)$ & $\mathrm{N}(\%)$ \\
\hline \multicolumn{4}{|l|}{ Gender } \\
\hline Male & $8803(41.9)$ & $9242(53.7)$ & $137(36.6)$ \\
\hline Female & $10566(50.3)$ & $5348(31.1)$ & $123(32.9)$ \\
\hline Unknown & $1648(7.8)$ & $2605(15.1)$ & $114(30.5)$ \\
\hline \multicolumn{4}{|l|}{ Age group } \\
\hline$<1$ year (infant) & $28(0.1)$ & $957(5.6)$ & $31(8.3)$ \\
\hline 1-9years (child) & $251(1.2)$ & $7906(46.0)$ & 47 (12.6) \\
\hline 10-19years & $3794(18.1)$ & $1418(8.2)$ & $43(11.5)$ \\
\hline 20-29years & 7044 (33.5) & 2304 (13.4) & $57(15.2)$ \\
\hline 30-39years & $4149(19.7)$ & $1511(8.8)$ & $54(14.4)$ \\
\hline $40-49$ years & 2170 (10.3) & $854(5.0)$ & $34(9.1)$ \\
\hline $50-59$ years & $1000(4.8)$ & $621(3.6)$ & $30(8.0)$ \\
\hline$\geq 60$ years & $742(3.5)$ & $658(3.8)$ & $17(4.5)$ \\
\hline Unclassified adult & $1650(7.9)$ & $731(4.3)$ & $43(11.5)$ \\
\hline Unrecorded & $189(0.9)$ & $235(1.4)$ & $18(4.8)$ \\
\hline \multicolumn{4}{|l|}{ Poison type } \\
\hline Pharmaceutical & $8512(40.5)$ & $5157(30.0)$ & $241(64.4)$ \\
\hline Pesticide & $6669(31.7)$ & $4196(24.4)$ & $31(8.3)$ \\
\hline Household/leisure & $4228(20.1)$ & $5617(32.7)$ & $23(6.1)$ \\
\hline Other & $1608(7.7)$ & 2225 (12.9) & $79(21.1)$ \\
\hline
\end{tabular}

The unclassified adult age category pertains to individuals aged over 19years, without a confirmed record of date of birth in the form.

unintentional poisoning was more associated with men. Consistent with other studies, women were found more likely than men to be at risk for self-inflicted poisoning admissions. ${ }^{11}$ Findings from USA similarly demonstrated a greater proportion of boys in poison exposures occurring in children younger than 13 years, then switching to a female predominance in teens and adults. ${ }^{12}$ Several international studies have highlighted that violent methods of self-harm, alcohol use disorders and economic stressors are associated with suicide attempts in men, whereas a history of sexual trauma and anxiety disorders are commonly associated with suicide attempts among women. ${ }^{13-15}$

Table 4 Distribution of poisoning exposure by poison subtypes

\begin{tabular}{|c|c|c|c|}
\hline & Intentional poisonings & Unintentional poisonings & Adverse reactions \\
\hline Poison type & $\mathbf{N}(\%)$ & $\mathbf{N}(\%)$ & $\mathbf{N}(\%)$ \\
\hline Unknown function & $48(0.2)$ & $58(0.3)$ & $0(0)$ \\
\hline Agricultural/garden & $150(0.7)$ & 218 (1.3) & $2(0.5)$ \\
\hline Environmental contaminant & $2(0)$ & $9(0.1)$ & $0(0)$ \\
\hline Food and beverages & $48(0.2)$ & $38(0.2)$ & $13(3.5)$ \\
\hline Household/leisure & $4228(20.1)$ & $5617(32.7)$ & $23(6.1)$ \\
\hline Industrial/commercial & $157(0.7)$ & $794(4.6)$ & $2(0.5)$ \\
\hline Mixture of agent & $317(1.5)$ & $24(0.1)$ & $2(0.5)$ \\
\hline Natural toxin & $65(0.3)$ & $855(5.0)$ & $52(13.9)$ \\
\hline Pharmaceutical & $8512(40.5)$ & $5157(30.0)$ & $241(64.4)$ \\
\hline Pesticide & $6669(31.7)$ & $4196(24.4)$ & $31(8.3)$ \\
\hline Substance of abuse & 765 (3.6) & $66(0.4)$ & $8(2.1)$ \\
\hline Others & $56(0.3)$ & $163(0.9)$ & $0(0)$ \\
\hline
\end{tabular}


The current study shows that there is a high proportion of unintentional poisoning cases involving children. Children are more susceptible to toxic chemicals because of the immaturity of many organ systems in detoxifying poison and their greater body surface that contributes to the fast rate of absorption through the skin. ${ }^{16} \mathrm{~A}$ WHO report revealed that common poisoning agents among children in high-income countries include pharmaceuticals, household products (eg, bleach, cleaning agents), pesticides, poisonous plants, and bites from insects and animals, whereas, common poisoning agents in low-income and middle-income countries are fuels such as paraffin and kerosene, pharmaceuticals and cleaning agents. ${ }^{17}$ Although the subtypes of causative agents for unintentional poisoning among children was not investigated further in this study, the main categories identified includes pharmaceuticals, household items and leisure products.

Ingestion remains the most common route of exposure for intentional poisoning. According to a previous report, pesticide ingestion constituted the greatest percentage of poisoning cases in Malaysia prior to 2008. ${ }^{18}$ However, the current study revealed that there is a change in this trend with pharmaceuticals topping the chart as the main poisoning causative agents in both the intentional and non-intentional categories. Enhanced exposure and easy availability of pharmaceutical products to the general public undoubtedly fuels a rise in the popularity of using such means for self-poisoning. ${ }^{190}$ Several reports from other poison control centres and hospitals revealed that the most common agents implicated in poisoning cases in developed countries and some developing countries were medicines sold over the counter such as paracetamol, cough and cold remedies, iron tablets, antihistamines and anti-inflammatory drugs. ${ }^{21}{ }^{22}$ Interestingly, studies also found that a vast majority of suicide attempters from the urban areas use psychotropic drugs such as tranquillisers and antipsychotics, ${ }^{23}$ whereas in rural areas, pesticides or other chemicals used in agriculture dominate. ${ }^{2425}$

From the outset, NPC has engaged and continues to engage in the education and training of healthcare professionals and the general public. Efforts are made to enable capacity building in the local community as well as awareness of issues surrounding poisoning. Activities organised by the NPC include workshops (eg, clinical management of pesticide poisoning), providing inhouse lectures to staff in tertiary healthcare settings, training community pharmacists, exhibitions and poison centre road shows.

Although the NPC is continuously improving its outreach strategies, financial restrictions have proven to be a hindrance in achieving its full potential as the prime organisation to help combat poisoning exposure in Malaysia. Online quizzes on the NPC website, as well as development of a poison centre mobile application are both examples of how the NPC could disseminate poisoning information to healthcare professionals and the general public in the future. More intense collaborations with governmental organisations such as the Ministry of Agriculture could give rise to annual health checks for those with occupations in the agricultural sector exposed to pesticides on a regular basis. Continued collaboration with national and internal organisations would ensure the development of outreach/educational programmes that are as dynamic as the poisoning trends being identified.

This study is subject to limitations. The trends observed in this study may not be wholly reflective of those currently present in Malaysia. The actual number of poisoning exposures may indeed have been higher during the study period (2006-2015) and may have been under-reported, as reporting of poisoning exposure to the NPC is not mandatory. The data documented in this study are derived from recorded calls by healthcare providers throughout the country and their enquiries relating to an actual or potential exposure to a substance requiring management in their respective healthcare facility. Not all poisoning exposures and overdoses have been reported to the NPC, especially if the cases are treatable and do not require additional assistance in terms of information on poisoning management and treatment. While the data undoubtedly provide a basis for the trend in cases of poisoning in Malaysia itself, important sociodemographic and regulatory differences might exist in different countries, hence the trends observed or the potential impact of these trends might be very different in other SouthEast Asian countries.

An important limitation worth highlighting is the lack of information on patients' outcomes and the severity of the poisoning based on any available poisoning severity scores. Additionally, the clinical features and patient management including the medical outcomes and therapies that were used were also not discussed in the current study. Medical outcomes could be of special interest as it is vital to know how severe these cases of poisoning were, in view of the fact that most were intentional exposures. This information, if available, could provide better insight into the depth of the problem; for example, a case of fatal intoxication could provide a basis for the implementation of strategies to reduce poisoning exposure.

Other information can be valuable for identifying strategies to reduce cases of poisoning. For example, information on single substance and polysubstance exposures was not available for analysis. It is also not possible with the current data to differentiate between cases of intentional abuse versus self-harm, an important detail that can provide an insight into the trend observed of the high number of intentional cases. Steps have been taken to include this information for future use.

\section{CONCLUSION}

Generally, the trend shows an increase in the number of poisoning exposure calls being handled by the poison centre, particularly those involving pharmaceuticals, 
pesticides and household items. The findings of this study show that emphasis and attention need to be given to poisoning induced due to pharmaceuticals, pesticides and household items. Using this as a reference, the NPC will be better informed on recent poisoning trends in Malaysia, thus enabling it to plan for more effective intervention strategies and public education programmes. Public awareness on the role of the NPC could also attract greater public participation towards poisoning control.

Acknowledgements The authors thank staff at the National Poison Centre Malaysia for their contribution to this report, with special thanks to other pharmacists from the National Poison Centre, Mohd Fadhli Razali, Nur Afni Amir, Sulastri Samsudin, Halilol Rahman Mohamed Khan, and Haslina Hashim. The publication fees for this article was supported by Universiti Sains Malaysia.

Contributors BT, MJ, AMA, NAAR and IAM designed this study. BT and MJ drafted the initial manuscript. AMA, IAM and AHD revised the manuscript. AMA, NAAR, AM and SMR were involved in the data collection. NAAR, BT and AMA were involved in the statistical analysis. All authors interpreted the analyses and data, and have scrutinised the final manuscript.

Funding The authors have not declared a specific grant for this research from any funding agency in the public, commercial or not-for-profit sectors.

Competing interests None declared.

Patient consent Not required.

Ethics approval The National Poison Centre Research Ethics Committee.

Provenance and peer review Not commissioned; externally peer reviewed. Data sharing statement No additional data are available.

Open access This is an open access article distributed in accordance with the Creative Commons Attribution Non Commercial (CC BY-NC 4.0) license, which permits others to distribute, remix, adapt, build upon this work non-commercially, and license their derivative works on different terms, provided the original work is properly cited, appropriate credit is given, any changes made indicated, and the use is non-commercial. See: http://creativecommons.org/licenses/by-nc/4.0/.

\section{REFERENCES}

1. Peden M, Oyegbite K, Ozanne-Smith J, et al. Poisoning: World Health Organization, 2008. (Accessed 16 Jan 2018).

2. Lee H-L, Lin H-J, Yeh T-Y, et al. The epidemiology and prognostic factors of poisoning. Epidemiology 2004;15:S179-80.

3. Spiller HA, Griffith JR. The value and evolving role of the U.S. Poison Control Center System. Public Health Rep 2009;124:359-63.

4. World Health Organization. World directory of poison centres. 2017 http://apps.who.int/poisoncentres/. (Accessed 30 Jan 2018).
5. Directory of poison centers. http://www.prn.usm.my/ (Accessed 31 Jan 2018).

6. Lin TJ, Walter FG, Hung DZ, et al. Epidemiology of organophosphate pesticide poisoning in Taiwan. Clin Toxicol 2008;46:794-801.

7. WHO. INTOX Data management system - component databases. http://www.who.int/ipcs/poisons/intox_dms_components/en/ (Accessed 1 Feb 2018).

8. Anderson BD, Seung H, Klein-Schwartz W. Trends in types of calls managed by U.S. poison centers 2000-2015. Clin Toxicol 2018;56:640-5.

9. Kerry R, Goovaerts P, Vowles M, et al. Spatial analysis of drug poisoning deaths in the American West, particularly Utah. Int J Drug Policy 2016;33:44-55.

10. Staines A, Staines A, Fitzpatrick $P$, et al. Urban-rural variation in mortality and hospital admission rates for unintentional injury in Ireland. Inj Prev 2005;11:38-42.

11. Ramisetty-Mikler S, Mains D, René A. Poisoning hospitalizations among Texas adolescents: age and gender differences in intentional and unintentional injury. Tex Med 2005;101:64-71.

12. Gummin DD, Mowry JB, Spyker DA, et al. 2016 Annual Report of the American Association of Poison Control Centers' National Poison Data System (NPDS): 34th Annual Report. Clin Toxicol 2017:55:1072-254.

13. Hawton K. Sex and suicide. Gender differences in suicidal behaviour. Br J Psychiatry 2000;177:484-5.

14. Zhang J, McKeown RE, Hussey JR, et al. Gender differences in risk factors for attempted suicide among young adults: findings from the Third National Health and Nutrition Examination Survey. Ann Epidemiol 2005;15:167-74.

15. Wunderlich U, Bronisch T, Wittchen HU, et al. Gender differences in adolescents and young adults with suicidal behaviour. Acta Psychiatr Scand 2001;104:332-9.

16. Adnan LHM, Kamaldin J, Mohamad N, et al. The risk of accidental chemical poisoning cases among children (12 Years Old) admitted to Hospital University Sains Malaysia: 5 years review. J Clin Toxicol 2013;3:177.

17. WHO. World report on child injury prevention. http://www.who.int/ entity/violence_injury_prevention/child/injury/world_report/en/index. html (Accessed 22 Jul 2018).

18. Awang R, Rahman AF, Abdullah WZ, et al. Trends in inquiries on poisoning: a five-year report from the National Poison Centre, Malaysia. Med J Malaysia 2003;58:375-9.

19. Camidge DR, Wood RJ, Bateman DN. The epidemiology of selfpoisoning in the UK. Br J Clin Pharmacol 2003;56:613-9.

20. Ahmadi A, Pakravan N, Ghazizadeh Z. Pattern of acute food, drug, and chemical poisoning in Sari City, Northern Iran. Hum Exp Toxicol 2010;29:731-8.

21. Rajka T, Heyerdahl F, Hovda KE, et al. Acute child poisonings in Oslo: a 2-year prospective study. Acta Paediatr 2007;96:1355-9.

22. CPSC.gov. https://www.cpsc.gov/ (Accessed 26 Jan 2018).

23. Tuan NV, Dalman C, Thiem NV, et al. Suicide attempts by poisoning in Hanoi, Vietnam: methods used, mental problems, and history of mental health care. Arch Suicide Res 2009;13:368-77.

24. Gunnell D, Bennewith O, Peters TJ, et al. Do patients who self-harm consult their general practitioner soon after hospital discharge? A cohort study. Soc Psychiatry Psychiatr Epidemiol 2002;37:599-602.

25. Thanh HT, Jiang GX, Van TN, et al. Attempted suicide in Hanoi, Vietnam. Soc Psychiatry Psychiatr Epidemiol 2005;40:64-71. 